\title{
Comentarios a la nueva regulación de la transparencia pública en España
}

\author{
Itxaso Gallastegui Ormaechea \\ Grado en Derecho por la Universidad de Deusto. \\ Máster en Investigación en Ciencias Jurídicas \\ por las Universidades de Deusto, \\ Pontificia Comillas y Ramon Llull.
}

\begin{abstract}
SUMARIO. I. A MODO DE INTRODUGCIÓN. II. ANÁLISIS SISTEMÁTICO DE LA LEY 19/2013 DE TRANSPARENGIA, AGCESO A LA INFORMAGIÓN PÚBLICA Y BUEN GOBIERNO. 1. Objeto. 2. Ámbito subjetivo de aplicación. 3. Publicidad activa. 4. Derecho de acceso a la información pública. A. Límites y excepciones. B. Procedimiento. Especial mención al silencio administrativo. 5. Consejo de Transparencia y Buen Gobierno. 6. Entrada en vigor. III. ESTUDIO DE OTRAS INICIATIVAS LEGISLATIVAS. 1. Ámbito estatal. A. Plan de Regeneración Democrática. B. Ley de racionalización y sostenibilidad de la Administración Local. 2. Ámbito autonómico. IV. CONCLUSIONES. V. BIBLIOGRAFÍA.
\end{abstract}

\section{RESUMEN:}

La transparencia puede desempeñar un papel esencial en el cambio de paradigma que requieren las Administraciones Públicas españolas para recuperar la credibilidad y la confianza en su gestión. Y es que constituye, sin lugar a dudas, el eje fundamental del buen curso de sus relaciones con la ciudadanía. En este sentido, la intención de confeccionar un adecuado marco normativo por medio de la aprobación de la Ley 19/2013 de transparencia, acceso a la información pública y buen gobierno, así como de otras iniciativas legislativas, tanto estatales, como autonómicas, parece reflejar la existencia de una verdadera voluntad política de otorgarle la importancia que en la realidad jurídica del país le corresponde, bien que la constatación de dicha voluntad estará sujeta, en todo caso, a las primeras evidencias de la implantación de una auténtica cultura de transparencia.

PALABRAS CLAVE:

Transparencia. Cambio de paradigma. Ciudadanía. Marco normativo. Voluntad política. 
ABSTRACT:

Transparency can play an essential role in the change of paradigm that is required by Spanish Public Administrations in order to restore the credibility and the confidence on their management. Indeed, it is beyond doubt the cornerstone of the good course of its relations with the citizens. In this sense, the intention to developing an appropriate regulatory framework trough the adoption of the Law 19/2013 of transparency, access to public information and good governance, as well as other legislative initiatives, both state and regional, seems to reflect the existence of a truth political will to endow the value that in the legal reality of the country belongs to it, although the confirmation of that will is going to be subjected, in any case, to the first evidences of the implementation of a genuine culture of transparency.

\section{KEYWORDS:}

Transparency. Change of paradigm. Citizens. Regulatory framework. Political will.

\section{A MODO DE INTRODUGCIÓN}

Es ineludible comenzar este estudio advirtiendo la manifiesta carencia que la base del funcionamiento de las Administraciones Públicas (en adelante AAPP) españolas ha mostrado las últimas décadas en lo que a la constitución de una poderosa cultura de transparencia se refiere. Si bien es cierto que, recientemente, la crisis económico-financiera ha sacudido todos los rincones del país y el contexto de globalización en que se ve inmersa la sociedad ha difuminado los distintivos de las relaciones, tanto internacionales como nacionales, públicas y privadas, el origen del problema señalado coincide con la instauración misma del régimen democrático en España. Y es que la transparencia administrativa en ningún momento ha ocupado el lugar que en su realidad institucional, jurídica, y social le corresponde. La insuficiente regulación acerca de la misma, junto a las frecuentes prácticas viciadas que ha llevado a cabo una numerosa parte del personal político y funcionario, ha menoscabado, incluso, la propia naturaleza democrática del Estado, situando a España, tal y como ha llegado a apuntar GUiCHOT REINA, "a la zaga de la democracias avanzadas"1.

\footnotetext{
${ }^{1}$ GUichot ReINA, Emilio. Transparencia y acceso a la información pública en España: Análisis y propuestas legislativas. Fundación Alternativas, Madrid, 2011, p. 17.
} 
Tanto la aplicación como el desarrollo de la transparencia deben contemplarse como eje fundamental de todo Estado democrático. Ya aseguró ARENA que "la transparencia y la democracia han devenido dos conceptos tan relacionados que no es posible citar uno sin pensar en el otro, de tal modo que parece obvio afirmar que no puede ejercerse una verdadera democracia sin transparencia y al revés" 2 . En contra, COTINO HUESO, aunque acepta que dicha vinculación "es obvia hasta el punto de afirmarse que no puede haber la una sin la otra", opina que "parece más acertado considerar[...]que la transparencia es un factor que refuerza o disminuye el carácter democrático del sistema" ${ }^{3}$. Y puede ser, precisamente, esta última noción que concibe la transparencia como elemento auxiliar de la democracia la razón que justifique su usual tratamiento como cuestión baladí en la actividad administrativa.

En este sentido, cabe asegurar que la consecución de la confianza de los ciudadanos hacia la actuación de las autoridades está sujeta, en gran medida, a la posibilidad de que éstos perciban una estrecha conexión a sus propósitos y resultados. $\mathrm{Al}$ respecto, es de destacar el papel esencial que la transparencia administrativa juega en la construcción de una fuerte y auténtica opinión pública en torno a las decisiones adoptadas y las iniciativas puestas en marcha por los poderes públicos y sus representantes, lo que a su vez supone un estímulo para su participación activa. DOS REIS CONDESSO añade que los objetivos de la misma persiguen, también, la función de potenciar "la eficacia, la racionalidad y la calidad de la prestación de los servicios públicos", a través de la supervisión ciudadana de su actividad ${ }^{4}$. Parece lógico pensar, por consiguiente, que todo Gobierno debe mostrarse convencido de que proporcionar la información que dispone resulta, además de correcto desde un punto de vista ético, sumamente importante para el adecuado desarrollo de su gestión. En la práctica, sin embargo, el déficit de claridad que, con carácter general, han mostrado los organismos públicos del país, ha relegado a un segundo plano el fin de alcanzar tan necesaria aproximación ciudadana.

Dicha situación se ha debido, primordialmente, al excesivo acotamiento que, de forma deliberada, se ha llevado a cabo respecto al principal mecanismo de ga-

\footnotetext{
${ }^{2}$ ARENA, Francisco Gregorio. "Transparencia administrativa y democracia". Revista Vasca de Administración Pública, no. 37, 1993, p. 9.

${ }^{3}$ COTino Hueso, Lorenzo. Teoría y realidad de la transparencia pública en Europa. Tirant lo Blanch, Valencia, 2003, p. 35.

${ }^{4}$ Dos Reis condesso, Fernando. Crisis del sistema político. Transparencia de los Poderes Públicos. Dykinson, Madrid, 2011, pp. 93-94.
} 
rantía de la transparencia administrativa: el derecho de acceso a los registros y documentos públicos. Los tres límites a su ejercicio previstos por el artículo 105. b) de la Constitución Española (en adelante CE), esto es, la seguridad y defensa del Estado, la averiguación de los delitos, y la intimidad de las personas, junto a los diversos preceptos que han recogido el desarrollo legislativo referente a los mismos, no han sido interpretados con el pertinente carácter restrictivo que requiere la seguridad jurídica para asegurar la efectividad del derecho en cuestión. Muestra de ello es la extendida impresión acerca de la urgencia de vencer el arraigado y predominante secretismo del proceder de las entidades públicas españolas. Ya en 1980, SERRA NAVARRO pronosticó la frecuente formación de "un sistema de prácticas cuya función consiste en ocultar a los ciudadanos el mecanismo de la AP y la información de que dispone" ${ }^{\text {. Y }}$ pese a que la idea de una transparencia absoluta de las AAPP resulta impracticable y equivocada, en tanto que, tal y como sostiene GARCÍA MACHO, la salvaguarda de determinadas condiciones, protegidas constitucionalmente, "constituye un freno y exige una ponderación entre los diversos bienes jurídicos en juego" 6 , no puede renunciarse a la aspiración de suscitar un cambio de paradigma del sistema administrativo con su máximo nivel como firme cimiento.

Puede suponerse, entonces, que la falta de delimitación de los términos y del alcance de aquellas circunstancias que se anteponen al ejercicio del aludido derecho de acceso ha debilitado su firmeza, y, por ende, la de la propia transparencia. Se ha anticipado, previamente, el carácter instrumental que el derecho de acceso a los registros y documentos públicos presenta respecto a esta última. El Tribunal Supremo, en Sentencia de 14 de noviembre de 2000, lo definió como "un derecho de los ciudadanos de los llamados de tercera generación[...] ]enraizado en el principio de transparencia administrativa" reconocido por la CE en el artículo 105. b) ${ }^{7}$. Así, y aunque más adelante se dará cuenta del debate doctrinal suscitado en torno a su naturaleza jurídica, es preciso percatarse, de acuerdo con SÁNCHEZ DE DIEGO FERNÁNDEZ DE LA RIVA, de la doble dimensión que se desprende de dicho concepto, en la medida en que lo determina como derecho subjetivo con protección constitucional, por un lado, y como exigencia de una AP

\footnotetext{
${ }^{5}$ SERra NAVARro, Pilar. Los archivos y el acceso a la documentación. Ministerio de Cultura, Madrid, 1980, p. 14.

${ }^{6}$ GARCía MaChO, Ricardo. "La transparencia en el sector público". En: BLASCO ESTEve, Avelino (Coord.). El Derecho Público de la crisis económica. Transparencia y sector público. Hacia un nuevo Derecho Administrativo. Instituto Nacional de Administración Pública, Madrid, 2011, p. 249.

7 Sentencia del Tribunal Supremo, sec. $6^{\text {a }}$, de 14 de noviembre de 2000. Ref. Aranzadi RJ $2001 / 425$.
} 
transparente, por otro ${ }^{8}$. SENDín GARCíA se ha pronunciado en la misma línea, bien que respecto a la segunda perspectiva ha agregado que la sujeción de la actividad de la AP al principio de publicidad, además de estimular indirectamente su eficacia y corrección, la somete en mayor medida al control social ${ }^{9}$.

La transparencia y el control social son, en definitiva, dos ideas entrelazadas, dado que la contribución de la segunda, junto con los hacederos efectos de otros mecanismos de vigilancia, inspección y evaluación, resulta imperiosa respecto a la primera. El control ciudadano cumple un cometido primordial incitando a los diversos organismos públicos a llevar a cabo una acción prudente y honesta, por lo que cabe indicar que el pretendido comportamiento transparente de las AAPP depende, en gran parte, de la incorporación de un permanente sistema de control. Dicho establecimiento derivaría, al mismo tiempo, en un destacado fortalecimiento democrático, solidez de la que tanto precisa, como se ha señalado, el entramado administrativo español. A fin de cuentas, ya declaró el político estadounidense SMITH que "todos los males de la democracia pueden curarse con más democracia"10, y la transparencia administrativa únicamente viene a ofrecer eso, más democracia.

Veamos, a continuación, lo que ofrece al respecto el nuevo marco normativo que, como evidente resultado de una firme reclamación ciudadana, así como de la experiencia y el asesoramiento europeo, han constituido los preceptos jurídicos, bien estatales, bien autonómicos, de reciente aprobación.

\section{ANÁLISIS SISTEMÁTICO DE LA LEY 19/2013 DE TRANS- PARENGIA, ACGESO A LA INFORMACIÓN PÚBLICA Y BUEN GOBIERNO}

El 9 de diciembre de 2013 vio, por fin, la luz la Ley 19/2013 de transparencia, acceso a la información pública y buen gobierno ${ }^{11}$, tras una lenta, poco ac-

\footnotetext{
${ }^{8}$ SÁNCHEZ DE DIEGO FERNÁNDEZ DE LA RIVA, Manuel (Coord.). El derecho de acceso a la información pública. Actas del Seminario Internacional Complutense, Madrid, 27 y 28 de junio de 2007, p. 10.

${ }^{9}$ SENDÍN GARCÍA, Miguel Ángel. "El derecho de acceso a los documentos administrativos: un instrumento esencial para la participación ciudadana". Revista de Estudios de la Administración Local y Autonómica, no. 294-295, 2004, p. 389.

${ }^{10}$ SMITH, Alfred Emanuel. "The future: Needed for America: Fewer Claims, More Growth". Time Magazine, Nueva York, 10 de noviembre de 1975: http://content.time.com/time/magazine/article/ 0,9171,913672,00.html (Última consulta, 7 de julio de 2014).

${ }^{11}$ España. Ley 19/2013, de 9 de diciembre, de transparencia, acceso a la información pública y buen gobierno. Boletín Oficial del Estado, 10 de diciembre de 2013, nº. 295, p. 97922.
} 
cesible y enmarañada tramitación. El Anteproyecto de Ley fue presentado por el Gobierno a consulta pública electrónica, por un periodo de quince días, el 26 de marzo de $2012^{12}$. Pese a las numerosas observaciones aportadas por los ciudadanos, el texto remitido pasado un mes a la Agencia Española de Protección de Datos, al Centro de Estudios Políticos y Constitucionales -que constituyó un grupo de trabajo para el análisis y debate de iniciativas al respecto-, y al Consejo de Estado, mostró escasas modificaciones. El Proyecto de Ley, por su parte, fue calificado el 4 de septiembre de $2012^{13}$. Es de evocar la convocatoria de diversas comparecencias de expertos en el Congreso de los Diputados para opinar sobre el mismo, si bien la postura inflexible del Grupo Parlamentario Popular únicamente permitió ciertas correcciones afines a su propuesta inicial. Finalmente, como ya se ha dicho, la Ley fue aprobada el 9 de diciembre de 2013, más de año y medio después de la publicación de su primer borrador, sumándose a la defensa llevada a cabo por su impulsor, el Partido Popular, el apoyo de Convergència i Unió, el Partido Nacionalista Vasco y Coalición Canaria, mientras que el Partido Socialista Obrero Español, Izquierda Plural, Unión, Progreso y Democracia, y gran parte del Grupo Mixto votaron en contra, por considerarla claramente insuficiente.

La nueva Ley está compuesta por cuarenta artículos, once más que el Proyecto de Ley, distribuyéndose, los mismos, en un Título Preliminar y tres Títulos más, y contiene, también, ocho disposiciones adicionales y nueve disposiciones finales. Es preciso, ciertamente, recuperar determinadas cuestiones suscitadas en torno a diversos mandatos del Proyecto de Ley para poder comparar y mostrar, seguidamente, la dimensión y la adecuación de esta norma jurídica. Y es que las críticas recibidas han sido importantes, tanto desde un punto de vista cuantitativo como cualitativo.

\section{Objeto}

El defecto más visible de la nueva legislación tiene que ver con la falta de eficacia que se le presupone a causa de su fraccionable contenido, reflejado, a grandes rasgos, en su propia denominación. La Ley debería haberse centrado, únicamente, en la transparencia de la actividad pública, cediendo la exposición de los

\footnotetext{
12 Véase:

http://www.access-info.org/documents/Anteproyecto_de_ley_de_Transparencia_Acceso_a_la_ Informacin_Pblica_y_Buen_Gobierno.pdf (Última consulta, 9 de julio de 2014).

${ }^{13}$ España. Proyecto de Ley 121/000019, de 4 de septiembre de 2012, de transparencia, acceso a la información pública y buen gobierno. Boletín Oficial de las Cortes Generales, 7 de septiembre de 2012, n. 19-1, serie A.
} 
principios de buen gobierno y la regulación de las sanciones derivadas de la vulneración de los mismos a un ulterior Código ético de carácter general ${ }^{14}$. Se hubiera ofrecido, de ese modo, un tratamiento particular a cada una de las materias que, pese a ser interdependientes, presentan cualidades exclusivas. El Buen Gobierno, sin embargo, es la otra parte consubstancial de la unidad normativa, tratándose, el Título referido al mismo, como se verá más adelante, del único que, desde la publicación de la Ley, el 10 de diciembre del pasado año, se encuentra en vigor, punto que puede comportar cierta desconfianza en torno a la verdadera voluntad del Ejecutivo español de apoyar el tema que a este estudio atañe.

La Exposición de Motivos de la Ley, una vez que determina la transparencia como eje fundamental de toda acción política, explica el triple alcance que la misma presenta: el incremento y refuerzo de la transparencia en la actividad pública; el reconocimiento y la garantía del acceso a la información; y el establecimiento de las obligaciones de buen gobierno y de las consecuencias jurídicas derivadas de su incumplimiento ${ }^{15}$. A pesar de que después recoge la afirmación de que, junto al importante avance que supone la Ley, el Estado impulsará y se adherirá a iniciativas multilaterales e instrumentos internacionales ya existentes sobre la materia, cabe señalar que no hace alusión expresa al Convenio (205) sobre Acceso a los Documentos Públicos del Consejo de Europa, Convenio al que la doctrina actual ha otorgado especial relevancia y que España no ha ratificado aún. MARZO PORTERA, por ejemplo, ha afirmado que "constituye el primer instrumento jurídico internacional vinculante que reconoce un derecho general de acceso a los documentos públicos y establece unas normas de mínimos inspiradas en las experiencias y prácticas de las legislaciones estatales"16. GUICHOT REINA, por su parte, si bien se ha pronunciado en términos similares, ha enlazado el estándar mínimo común que según él ha fijado el Convenio, con la consecuente posibilidad proporcionada a los Estados de actuar de modo ambicioso en prácticamente todos los puntos del ámbito de la transparencia ${ }^{17}$.

${ }^{14}$ En palabras de OLMEDO PALACiOS, se trata de un "cuerpo extraño que se introduce en lo que debería ser una norma centrada en el derecho de acceso como presupuesto de un Estado democrático[...]". Olmedo PALAcios, Manuel. "La Ley 19/2013, de 9 de diciembre, de transparencia, acceso a la información y buen gobierno". Diario La Ley, n. 8237, LA LEY, 2014, p. 11.

15 Dicho triple alcance vuelve a ser concretado por el artículo 1 que compone el Título Preliminar de la Ley, precepto referido al objeto de la misma.

16 MARZo PORTERA, Ana. "Los límites legales a un gobierno transparente". Actualidad Jurídica Aranzadi, $n^{\circ}$.841/2012, Aranzadi, 2012, p. 1.

17 GUICHOt REINA, Emilio. Transparencia y acceso a la información en el Derecho europeo. Cuadernos Universitarios de Derecho Administrativo, Derecho Global, Global Law Press, Sevilla, 2011, pp. 71 72. 
En cualquier caso, admitiendo las numerosas carencias de la regulación existente y las insatisfacciones, tanto sociales como políticas, derivadas de las mismas, se pone de manifiesto el buen propósito de crear "un marco jurídico acorde a los tiempo y los intereses ciudadanos".

\section{2. Ámbito subjetivo de aplicación}

Uno de los cambios más significativos que la Ley presenta respecto al Proyecto de Ley está ligado a la ampliación de su ámbito subjetivo de aplicación llevada a cabo en el Capítulo I de su Título I, referente a la transparencia de la actividad pública.

Sus disposiciones apuntan, de esta manera, junto a todas las AAPP ${ }^{18}$, los órganos del Poder Legislativo y Judicial, y diversos organismos constitucionales y estatutarios, a determinadas entidades públicamente relevantes y/o perceptoras de fondos públicos, en relación con sus actividades sujetas a Derecho Administrativo. Entre estas últimas se encuentran el Banco de España y la Casa Real. Como es bien sabido, la Casa Real carece de potestad legislativa y judicial, por lo que es de destacar que hubiera sido más acertado englobar, íntegramente, todos sus cometidos, apreciación que puede ajustarse, asimismo, a gran parte de las actividades de las entidades citadas en último lugar.

Pero, aunque mediante tal inclusión se haya dado respuesta a una de las principales reclamaciones, tanto doctrinales como sociales, dirigidas al texto previo, lo cierto es que tal correspondencia sólo ha sido relativa: el artículo 3, atinente a partidos políticos, sindicatos y organizaciones empresariales, por un lado, y a entidades privadas beneficiarias de cuantías específicas procedentes de ayudas o subvenciones públicas, por otro, supedita a los mismos, únicamente, a los preceptos del Capítulo II de este Título, sobre publicidad activa, perdiendo, así, la oportunidad de equiparar su posición al del resto de sujetos obligados.

El artículo 4, por su parte, aunque somete a las personas físicas y jurídicas, distintas de las referidas anteriormente, que presten servicios públicos o ejerzan potestades administrativas, a la obligación de suministrar información a la AP, organismo o entidad a la que se encuentren vinculadas, presenta una clara falta, puesto que no concreta el alcance de dicho deber. Además, en lo que a los adjudicatarios del sector público concierne, solamente extiende tal obligación en los

${ }^{18}$ En torno a su concepto, puede considerarse superado el significado restrictivo que, en ocasiones, les es asignado, dado que entre los apartados f) e i) del artículo 2 la Ley incorpora sujetos vinculados a las mismas. 
términos previstos en el respectivo contrato, previsión que, según OLMEDO PALACIOS significa "dejar la puerta abierta a pactos derogatorios de las obligaciones legales en una materia especialmente sensible" $"$.

Finalmente, tampoco pasa desapercibida, pese a las constantes desavenencias mostradas y enmiendas presentadas, la ausencia de alusión, en los artículos citados, a los diferentes grupos de presión o lobbies, cuya actividad influye, potencialmente, en el proceso de toma de decisiones de determinadas áreas -la urbanística, sobre todo- del sistema público español y que la Unión Europea (en adelante, UE) ya reguló, en junio de 2008, mediante la creación del Registro de transparencia $^{20}$.

\section{Publicidad activa}

Como se ha avanzado, el Capítulo II del Título I contiene medidas sobre publicidad activa. FERNÁNDEZ RAMOS considera que debido al progreso de las nuevas tecnologías, "los originales deberes de publicidad pro-activa[...] se han desarrollado espectacularmente, de tal modo que la publicidad activa ha pasado a cumplir un papel esencial en las leyes de transparencia, como la otra cara del derecho de acceso" 21 . Tanto es así que esta misma Ley ofrece a su regulación el Capítulo antepuesto al referente al derecho de acceso a la información pública.

Con carácter general, el contenido de los mandatos es correcto: impone a las AAPP el deber de publicar, "en las correspondientes sedes electrónicas o páginas web y de una manera clara, estructurada y entendible para los interesados", la información "cuyo conocimiento sea relevante para garantizar la transparencia de su actividad relacionada con el funcionamiento y control de la actuación pública". Se aprecian, no obstante, determinadas imprecisiones en su redacción. Muestra de ello es el primer punto del artículo 5 que, pese a exigir periodicidad y actualización respecto a la obligación mencionada, no concreta los plazos en cuestión. Tampoco se especifican las consecuencias jurídicas de su omisión ${ }^{22}$. De todas formas, hay que poner de relieve el agre-

19 OLMEdo Palacios, Manuel. "La Ley 19/2013, de 9 de diciembre, de transparencia, acceso a la información y buen gobierno", op. cit., p. 4.

${ }^{20}$ Véase: http://ec.europa.eu/transparencyregister/info/homePage.do?locale=es (Última consulta, 9 de julio de 2014).

${ }^{21}$ FERnÁndez Ramos, Severiano. Panorámica general sobre transparencia y gobierno abierto. El estado actual de la situación en el Estado español. Ponencia presentada durante la sesión de Q-Epea en el Parlamento Vasco sobre Transparencia y Gobierno abierto de las instituciones y Administraciones Públicas, Vitoria, 23 de octubre de 2013.

22 Se hace referencia, únicamente, al incumplimiento reiterado de las obligaciones de publici- 
gado de dos nuevos artículos (9 y 11), en comparación con el Proyecto de Ley, concernientes, al control de su cumplimiento, el primero, y a los principios técnicos de accesibilidad, interoperabilidad y reutilización a los que tienen que adecuarse las prescripciones que debe respetar la información publicada contenida en el Portal de la Transparencia, el segundo.

Es el referido Portal de la Transparencia, precisamente, el órgano que, una vez desarrollado por la Administración General del Estado (en adelante AGE) ${ }^{23}$, se encargará de facilitar el acceso de los ciudadanos a la información relativa a su ámbito de actuación que sea solicitada con mayor frecuencia. La creación del mismo viene a responder, en cierto grado, a las insistentes peticiones realizadas al respecto por la organización no gubernamental "Transparencia Internacional" que lucha contra la corrupción, aunque hay que resaltar que su funcionamiento no ha sido determinado por el artículo 10 que lo regula. Además, bien que, con el propósito de evitar duplicidades, parece acertado prever un único Portal de acceso a toda la información de la AGE, el citado autor advierte que no queda claro si la Ley obliga a incluir, también, la de los múltiples organismos y entidades dependientes o vinculadas a la misma. Y añade que, en ese caso, "la información debería estar desglosada por cada organismo o entidad, pues de lo contrario carecería de significación alguna" ${ }^{24}$.

dad activa, estableciendo su "consideración de infracción grave a los efectos de aplicación a sus responsables del régimen disciplinario previsto en la correspondiente normativa reguladora" (artículo 9.3).

${ }^{23}$ El Gobierno ya ha impulsado el desarrollo y puesta en marcha del futuro Portal. Más concretamente, el 5 de marzo, los secretarios de Estado de Administraciones Públicas y Relaciones con las Cortes suscribieron un acuerdo de colaboración por el que el Portal y sus contenidos dependerán del Ministerio de la Presidencia, mientras que el diseño tecnológico, desarrollo informático y mantenimiento técnico correrán a cargo de Hacienda, y el 29 de julio, la vicepresidenta del Gobierno presidió una reunión para la implantación de la Oficina de la Transparencia y Acceso a la Información, órgano encargado de garantizar la aplicación de los principios y derechos derivados de la Ley del que penderá el Portal. Para más detalle, véase: http://www.abc.es/espana/20140306/abci-transparencia-acuerdo-portal-201403052149. html y http://www.abc.es/espana/20140729/abci-oficina-transparencia-empieza-201407291350.html, respectivamente (Última consulta, 30 de julio de 2014).

${ }^{24}$ FERNÁNDEZ RAMOS, Severiano. "Transparencia y Acceso a la Información Pública". En: FERNÁNDEZ Ramos, Severiano, y PÉREZ MOnguió, José María. Transparencia, Acceso a la Información Pública y Buen Gobierno. Ley 19/2013, de 9 de diciembre. Aranzadi, Pamplona, 2014, p. 144. 


\section{Derecho de acceso a la información pública}

El derecho de acceso a la información pública está recogido en el Capítulo III del Título I. Resulta imperioso comenzar dando cuenta de las divergentes opiniones que ha provocado el carácter, enlazado al artículo 105. b) de la CE, que le ha atribuido el artículo 12 de la Ley. Una parte de la doctrina aplaude el progreso que la salvaguarda jurídica del derecho presenta debido a la ampliación de contenido realizada respecto a los artículos 35. h) y 37 de la Ley 30/1992, de 26 de noviembre, de Régimen Jurídico de las Administraciones Públicas y del Procedimiento Administrativo Común (en adelante, LRJAP-PAC) ${ }^{25}$, por una parte, y al reconocimiento de su naturaleza universal, por otra ${ }^{26}$. Se trata, generalmente, de autores que contemplan el derecho de acceso como un simple derecho constitucional. Al respecto, VELASCO RICO, entre otros, opina que el derecho de acceso "debe considerarse, todavía,[...] un derecho constitucional de configuración legal", dado que no existe, ni pronunciamiento jurisprudencial del Tribunal Constitucional, ni manifestación de las Cortes Generales, que indiquen lo contrario $^{27}$. Pero también hay quien ve insuficiente el tratamiento que la Ley le ha otorgado. Esta otra parte de la doctrina, cada vez mayor, trabaja a favor de la aceptación de su carácter fundamental, integrado en la libertad de información prevista por el artículo 20.1.d) de la CE. GUICHOT REINA alude a la pertinencia de esta segunda perspectiva si se pretende "extender su ámbito subjetivo a todos los poderes públicos de cualquier ámbito territorial, y dotarlo de la mayor garantía que supone la reserva de ley orgánica y el recurso de amparo constitucional" 28 .

A pesar de no haberse embarcado ahora en el camino hacia el reconocimiento de un derecho fundamental de acceso - al que, posiblemente, deba aco-

${ }^{25}$ Éstos, como es bien sabido, únicamente se refieren al derecho de los ciudadanos a acceder a la información pública, archivos y registros, en los términos y con las condiciones establecidas en la CE, la Ley de transparencia, acceso a la información pública y buen gobierno, y demás leyes que resulten de aplicación. Son mandatos visiblemente escasos, dado que no concretan obligación alguna al respecto.

${ }^{26}$ ENÉRIZ OLAECHEA, por ejemplo, se ha expresado en esta línea. ENÉRIZ OLAECHEA, Francisco Javier. "El proyecto de Ley de Transparencia: transparencia de la actividad pública y publicidad activa". Revista Aranzadi Doctrinal, n. 1/2013, 2013, pp. 2-3.

27 VELASCO RICO, Clara Isabel. "Análisis en clave competencial del Proyecto de Ley estatal sobre Transparencia, Acceso a la Información Pública y Buen Gobierno". Revista d’Estudis Autonòmics $i$ Federals, ${ }^{\circ}$. 17, 2013, p. 285.

${ }^{28}$ GUICHOT REINA, Emilio. "El proyecto de ley de Transparencia y acceso a la información pública y el margen de actuación de las Comunidades Autónomas". Revista Andaluza de Administración Pública, no. 84, 2012, p. 102. 
gerse a medio plazo ${ }^{29}$, el Estado, a través de la nueva regulación que expone en el articulado de la Ley, mejora, inobjetablemente, la protección jurídica que le confiere al mismo. Muestra de ello es el alcance del concepto de información pública que expone su artículo 13, puesto que se refiere a "los contenidos o documentos, cualquiera que sea su formato o soporte, que obren en poder de alguno de los sujetos incluidos en el ámbito de aplicación de este título y que hayan sido elaborados o adquiridos en el ejercicio de sus funciones".

\section{A. Límites y excepciones}

En lo que al amplio listado de límites al derecho de acceso del artículo 14 concierne, cabe indicar que su contenido coincide, en su mayoría, con lo establecido por la normativa europea ${ }^{30}$. Ello no obstante, sigue siendo una regulación indeterminada, dado que, finalmente, no se ha efectuado la concreción terminológica, requerida por gran parte de la doctrina tras el análisis del texto previo, que aclararía los confines de su aplicación. ¿Cuáles son los límites de los límites?

Se puede aludir al artículo 13 de la Ley 27/2006, de 18 de julio, por la que se regulan los derechos de acceso a la información, de participación pública y de acceso a la justicia en materia de medio ambiente ${ }^{31}$, que detalla las excepciones a la obligación de facilitar la información material, como muestra de la precisión que debía haberse realizado en este caso.

\footnotetext{
${ }^{29}$ En el ámbito internacional, tras varias declaraciones políticas al respecto, ya ha sido reconocido por la Corte Interamericana de Derechos Humanos por medio de la Sentencia del "Caso Claude Reyes y otros contra Chile" de 19 de septiembre de 2006. La doctrina del Tribunal Europeo de Derechos Humanos parece haber tomado, también, dicha dirección, sobre todo tras los dos fallos emitidos en 2009 - del "Caso Társaság a Szabadságjogokért c. Hungría", por un lado, y del "Caso Kenedi c. Hungría", por otro. Y en la esfera estatal, si bien es cierto que todavía no ha tenido lugar ningún pronunciamiento judicial, la aceptación del carácter fundamental del derecho a la protección de datos personales, sin que éste esté expresamente formulado en la CE y considerando, por consiguiente, que la lista de derechos recogida en la misma no constituye un numerus clausus, abre las puertas a que se produzca, bien por determinación legislativa, bien por interpretación constitucional, dicho reconocimiento.

${ }^{30}$ Ejemplo de ello son el artículo 4 del Reglamento nº 1049/2001, de 30 de mayo de 2001, relativo al acceso del público a los documentos del Parlamento Europeo, del Consejo y de la Comisión, y el artículo 3, referente a los posibles límites al acceso a los documentos públicos, del mencionado Convenio del Consejo de Europa, entre otros.

${ }^{31}$ España. Ley 27/2006, de 18 de julio, por la que se regulan los derechos de acceso a la información, de participación pública y de acceso a la justicia en materia de medio ambiente. Boletín Oficial del Estado, 19 de julio de 2006, nº. 171, p. 27109.
} 
De forma excepcional, la protección de datos personales es elucidada, minuciosamente, por el artículo 15 de la Ley. Sin embargo, es de señalar que, el primer párrafo que contenía el Proyecto de Ley, referente a las disposiciones aplicables en los diversos casos de solicitud de acceso relativa a información pública con datos de carácter personal, ha sido suprimido. Y aunque, acaso, pueda darse por sentado lo expuesto en él, tampoco en este punto se cierra la puerta a posibles controversias.

Es preciso resaltar, esencialmente, que desde su propia Exposición de Motivos, la Ley anuncia una aplicación de los límites previstos "atendiendo a un test de daño y de interés público en la divulgación y de forma proporcionada y limitada por su objeto y finalidad".

Cabe retornar, por lo demás, al artículo 5.3 de la Ley, en la medida en que fija, de forma acertada, la previa disociación de los datos especialmente protegidos que pudiera contener la información solicitada, para llevar a cabo su publicidad. Y de igual manera, el artículo 16 prevé el acceso parcial cuando los límites del artículo 14 no afecten a la totalidad de la información. Hay que advertir que la Ley presenta una redacción ampliada de este último mandato, puesto que, a diferencia del Proyecto de Ley, establece la obligación de indicar al solicitante "que parte de la información ha sido omitida". Se puede inferir la influencia del contenido de preceptos equivalentes de la esfera europea en dicha especificación. El artículo 5.6 del citado Convenio del Consejo de Europa, por ejemplo, establece lo siguiente: "Una autoridad pública que rechaza el acceso total o parcial a un documento oficial deberá dar las razones de la denegación. El solicitante tiene el derecho a recibir sobre su petición una justificación escrita de la denegación de esa autoridad pública".

\section{B. Procedimiento. Especial mención al silencio administrativo}

En lo que al procedimiento de acceso a la información pública respecta, los artículos 17-22 de la Ley han acogido ciertas pinceladas en aras de cubrir pequeñas carencias que presentaba el Proyecto de Ley. De este modo, en el primer punto del artículo 17 se ha añadido el supuesto de solicitud de información en posesión de quien presta servicios públicos o ejerce potestades administrativas, y en el tercero se ha indicado, de forma explícita, que el solicitante no está obligado a motivar su solicitud. Igualmente, ese mismo precepto prevé, en un nuevo apartado, la posibilidad de dirigirse a la AP, en el territorio que la misma radique, en cualquiera de las lenguas cooficiales del Estado.

El proceso, en líneas generales, destaca por el dinamismo que, por medio del establecimiento de cortos plazos, demanda, tanto a los ciudadanos que ejercen su derecho de acceso, como a las AAPP poseedoras de la información, en sus di- 
versas fases o etapas, esto es, en la solicitud, tramitación, resolución y formalización.

Pese a ello, debe afirmarse que la Ley flaquea, incuestionablemente, al fijar un doble silencio administrativo negativo: el primero, en su artículo 20.4, cuando transcurre el tiempo máximo para resolver sin que se haya dictado y notificado resolución expresa, y el segundo, en su artículo 24.4, cuando tiene lugar la reclamación ante el Consejo de Transparencia y Buen Gobierno y éste no determina en un plazo de tres meses.

Se puede ver, a simple vista, que la propia Ley presenta marcadas contradicciones al respecto: Atendiendo a la obligación impuesta por el artículo 20.2 de motivar aquellas resoluciones que denieguen el acceso, concedan el acceso parcial o a través de una modalidad distinta a la solicitada, o permitan el acceso cuando haya habido oposición de un tercero, cabría suponer la previsión legal del silencio administrativo positivo. De hecho, la integración en el ordenamiento jurídico español de las normas de la UE, y más concretamente, de la Directiva 2006/123/CE del Parlamento Europeo y del Consejo, relativa a los servicios en el mercado interior ${ }^{32}$, vendría a corroborar tal deducción, en la medida en que su artículo 13.4, a falta de respuesta en el plazo fijado, considera concedida la autorización, salvo que exista razón imperiosa de interés general, incluidos los legítimos intereses de terceros, que justifiquen un régimen distinto.

Tal y como indica RAZQUIN LIZARRAGA, en España, el proceso de transposición de la Directiva mencionada "se ha llevado a cabo en dos niveles", a través de la aprobación de la Ley 17/2009, de 23 de noviembre, sobre el libre acceso a las actividades de servicios y su ejercicio ${ }^{33}$, por una parte, y de su implantación en los distintos sectores, mediante la Ley 25/2009, de 22 de diciembre, de modificación de diversas leyes para su adaptación a dicha Ley ${ }^{34}$, por otra ${ }^{35}$. El artículo 6 de la Ley 17/2009, precisamente, establece que los procedimientos y trámites

${ }^{32}$ Directiva 2006/123/CE del Parlamento Europeo y del Consejo, de 12 de diciembre de 2006, relativa a los servicios en el mercado interior, Diario Oficial de la Unión Europea, n . L376, de 27 de diciembre de 2006, p. 36.

${ }^{33}$ España. Ley 17/2009, de 23 de noviembre, sobre el libre acceso a las actividades de servicios y su ejercicio. Boletín Oficial del Estado, 24 de noviembre de 2009, nº. 283, p. 99570.

${ }^{34}$ España. Ley 25/2009, de 22 de diciembre, de modificación de diversas leyes para su adaptación a la Ley sobre el libre acceso a las actividades de servicios y su ejercicio. Boletín Oficial del Estado, 23 de diciembre de 2009, nº. 308, p. 108507.

35 RAZQUin liZARRAGA, José Antonio. "De la intervención administrativa previa al control a posteriori: la reforma del procedimiento administrativo común a consecuencia de la directiva de servicios". Revista Aranzadi Doctrinal, no. 2/2010, Aranzadi, 2010, pp. 3-4. 
para la obtención de las autorizaciones a que se refiere deben "garantizar la aplicación general del silencio administrativo positivo y que los supuestos de silencio administrativo negativo constituyan excepciones previstas en una norma con rango de ley justificadas por razones imperiosas de interés general" 36 .

Si bien el caso que aquí atañe no presenta dificultad alguna respecto a la primera condición - es una determinación realizada en una norma con rango legal-, comprobar si se cumple el segundo requisito sustantivo, que exige una argumentación con base en razones imperiosas de interés general, resulta más complicado.

En este sentido, es necesario advertir que la disposición adicional cuarta de la citada Ley 25/2009 salva el silencio administrativo negativo previsto por procedimientos regulados por normas con rango de ley o de Derecho comunitario con anterioridad a su entrada en vigor. Por ello, podrá haber quien se acoja a dicho precepto para interpretar -tomando con pinzas- que las ínfimas alusiones al derecho de acceso a la información pública recogidas por la LRJAP-PAC, junto a las referencias realizadas por diversas normas sectoriales, ya regulaban, en cierto modo, el procedimiento de acceso que la Ley 19/2013 desarrolla y especifica ahora, para concluir su reconocimiento como uno de sus supuestos. Debería tratarse, no obstante, de un posicionamiento minoritario.

Bien que la Ley objeto de estudio hace constantes alusiones a la cuestión del conflicto de intereses y a la necesidad de llevar a cabo la ponderación de los mismos, lo cierto es que no menciona expresamente las circunstancias que, en su caso, constituirían razones imperiosas de interés general. Así pues, pese a no tener que coincidir necesariamente con el significado atribuido a nivel interno, la jurisprudencia del Tribunal de Justicia de la UE ha configurado un riguroso listado de asuntos que comprende el concepto señalado ${ }^{37}$, y cabe asegurar que la mayoría de dichos casos -por razón de materia, se prescinde de algunos de ellos- están previstos como límites al derecho de acceso en la Ley 19/2013. De ahí que parezca

\footnotetext{
${ }^{36}$ Se observa la adecuación del precepto mencionado a la pretensión de generalizar el uso del silencio administrativo positivo, de acuerdo a la línea marcada por los mandatos de otras normas del ámbito europeo, entre las que se encuentra, por ejemplo, el citado artículo 5.6 del Convenio (205) sobre Acceso a los Documentos Públicos del Consejo de Europa.

${ }^{37}$ Concretamente, los siguientes: el orden público, la seguridad pública, la protección civil, la salud pública, la preservación del equilibrio financiero del régimen de seguridad social, la protección de los derechos, la seguridad y la salud de los consumidores, de los destinatarios de servicios y de los trabajadores, las exigencias de la buena fe en las transacciones comerciales, la lucha contra el fraude, la protección del medio ambiente y del entorno urbano, la sanidad animal, la propiedad intelectual e industrial, la conservación del patrimonio histórico y artístico nacional y los objetivos
} 
razonable sostener que el requisito de justificación por razones de interés general, aunque de forma indirecta, también se cumple en este caso, y que, por consiguiente, siempre que se apoye en alguno de los límites marcados por los artículos 14 y 15 de la Ley, el doble silencio administrativo negativo recogido en la misma estará legitimado.

Ello no obstante, el artículo 20.6 alberga una segunda contradicción. No lo hace, desde luego, por entender grave la infracción que constituye "el incumplimiento reiterado de la obligación de resolver en plazo", sino por sancionar considerablemente la repetición de una inactividad que, previamente, permite de forma explícita. La especificación expuesta en este punto parece indicar que el legislador coincide en que ofrecer amparo a la AP -o al Consejo de Transparencia y Buen Gobierno, en su caso- en los preceptos señalados para no tener que conceder la pertinente explicación acerca de la denegación de una solicitud de acceso, la concesión del acceso parcial o a través de una modalidad distinta a la solicitada, o el permiso de acceso cuando ha habido oposición de un tercero, va en contra de los propios fines de la Ley, en la medida en que supone un claro sinsentido hablar, así, de garantía de atención ciudadana, y por ende, de transparencia de la acción pública. Y pese a que diversas voces se han alzado a favor del establecimiento y de la adecuación del silencio administrativo positivo, tal sustitución no solucionaría, de ningún modo, el proble$\mathrm{ma}^{38}$. Una Ley de estas características debe basarse, necesariamente, en el continuo diálogo entre las AAPP y los ciudadanos, con fundamento en un claro, consistente y coherente razonamiento para la adopción de las disímiles posturas y decisiones. Debe pretender la instauración de un modelo de gestión de los intereses públicos en el que todos los sujetos desarrollen un papel activo y correlativo. Y, ciertamente, una correcta focalización del deber de informar, eludiendo la aplicación del silencio administrativo, en tanto que principal freno a la motivación de la ciudadanía de conocer los detalles de la actuación pública -y de participar en ella-, hubiera mejorado e impulsado tal interacción.

de la políticas social y cultural. Véase: RAZQUIN LIZARRAGA, José Antonio. "El impacto de la directiva de servicios en el procedimiento administrativo: autorización, declaración responsable y comunicación". Revista furídica de Navarra, nº. 49, 2010, p. 97.

38 GUichOT REINA sale en defensa del silencio administrativo negativo ante las duras críticas -a su juicio absolutamente injustificadas- que éste ha recibido por parte de autores posicionados a favor del silencio administrativo positivo. Afirma, por ejemplo, que mientras que el primero es "una garantía frente al incumplimiento de una obligación", el silencio positivo constituye un "acto declarativo de derechos que, en caso de no hacerse efectivos, cabe reclamar judicialmente sin que el Tribunal pueda entrar en el fondo del asunto". Asimismo, califica de "pedagógica y de fomento del cumplimiento" la medida que la Ley recoge en su artículo 20.6. Puede comprobarse que en ningún caso contempla la opción de eliminar su aplicación. GUICHOT REINA, Emilio. Transparencia y buen gobierno. Estudio y Ley. Aranzadi, Pamplona, 2014, p. 26. 


\section{Consejo de Transparencia y Buen Gobierno}

Se ha procedido, finalmente, a la creación y regulación de un nuevo órgano de supervisión y control para garantizar la correcta aplicación de la Ley objeto de estudio. El nacimiento ex novo del Consejo de Transparencia y Buen Gobierno aparca, así, la originaria pretensión de otorgar competencias en la materia a un organismo ya existente, atribución que, según la Exposición de Motivos del Proyecto de Ley, respondía a objetivos de "austeridad exigida por las actuales circunstancias económicas". Además, mientras que a este último, esto es, a la Agencia Estatal de Transparencia, Evaluación de las Políticas Públicas y la Calidad de los Servicios, sólo se le habría asignado el cometido de resolver reclamaciones potestativas y previas a la vía judicial creadas ad hoc para sustituir los recursos administrativos, al nuevo ente se le otorgan competencias de carácter general: promocionar la cultura de transparencia en la actividad de la AP, controlar el cumplimiento de las obligaciones de publicidad, salvaguardar el ejercicio del derecho de acceso a la información pública y garantizar la observancia de las disposiciones de buen gobierno.

El Consejo de Transparencia y Buen Gobierno, regulado en el Título III de la Ley y compuesto por una Comisión y un Presidente -que a su vez lo es de la Comisión-, se configura como un organismo público con personalidad jurídica propia y plena capacidad de obrar. El segundo apartado del artículo 33.2 añade, asimismo, que "actúa con autonomía y plena independencia en el cumplimiento de sus fines". Y precisamente, para asegurar tales rasgos en el ejercicio de sus funciones, la Ley fija, en lo que al nombramiento del Presidente concierne, mandatos no renovables de cinco años que deben contar con el refrendo, por mayoría absoluta, del Congreso de Diputados, y en lo que a la cesión en su cargo respecta, la separación acordada por el Gobierno sólo en casos tasados de incumplimiento grave de sus obligaciones, incapacidad permanente para llevar a cabo su cometido, incompatibilidad sobrevenida o condena por delito doloso. Ello no obstante, la Comisión Europea ha considerado, en el Anexo relativo a España del Informe sobre la Lucha Contra la Corrupción en la UE, de 3 de febrero de 2014, remitido al Consejo y al Parlamento Europeo, que ésta no prevé "garantías suficientes para la independencia de su mecanismo de control independiente" ${ }^{\prime 9}$. En este sentido, SÁNCHEZ DE DIEGO FERNÁNDEZ DE LA RIVA ha asegurado que, ciertamente, no se trata de una autoridad independiente, sino dependiente del Ministerio de

\footnotetext{
${ }^{39}$ Véase: Informe de la Comisión al Consejo y al Parlamento sobre la lucha contra la corrupción en la UE: http://ec.europa.eu/dgs/home-affairs/what-we-do/policies/organized-crime-andhuman-trafficking/co rruption/anti-corruption-report/docs/2014_acr_spain_chapter_es.pdf (Última consulta, 14 de julio de 2014).
} 
Hacienda y Administraciones Públicas, y ha apuntado al estatus de la Agencia Española de Protección de Datos Personales como contrapunto de dicha carencia $^{40}$.

Pero la polémica no acaba ahí, ya que el Consejo de Ministros ha incumplido el deber impuesto por la disposición final séptima de la Ley de aprobar un Real Decreto que regule el Estatuto orgánico del nuevo ente en el plazo de tres meses desde su publicación, esto es, antes del 10 de marzo de 2014. Y de momento, no hay noticias al respecto.

\section{Entrada en vigor}

Se ha avanzado, en el apartado referido al objeto de la Ley, que en la actualidad únicamente se encuentra en vigor su Título II, que recoge los principios de buen gobierno y establece las consecuencias jurídicas derivadas de su incumplimiento $^{41}$. En relación al resto del articulado, el Proyecto de Ley ya fijó una vacatio legis de un año desde su publicación en el Boletín Oficial del Estado, previsión que la disposición final novena de la Ley no sólo no ha salvado, sino que ha sobrepasado, añadiendo una tercera regla que establece que "los órganos de las $\mathrm{Co}^{-}$ munidades Autónomas y Entidades Locales dispondrán de un plazo máximo de dos años para adaptarse a las obligaciones contenidas" en la misma. Se determina, así, una entrada en vigor escalonada que, según la Exposición de Motivos, atiende "a las especiales circunstancias que conllevará la aplicación de sus diversas disposiciones", si bien no las concreta o elucida de forma expresa. De la revisión del texto legal cabría inferir que dicha expresión apunta a las insuficiencias técnicas que presentaba el propio contexto material en el que tuvo lugar la publicación de la Ley, puesto que faltaba dar importantes pasos: desarrollar el Portal de la Transparencia; establecer las unidades de información; aprobar el Estatuto orgánico del Consejo de Transpa-

\footnotetext{
${ }^{40}$ SÁNCHEZ DE DIEGO FERNÁNDEZ DE LA RIVA, Manuel. El principio de transparencia y el derecho de acceso a la información pública. Ponencia presentada durante el XII Congreso de Constitucionalistas de España en la vieja Universidad de Salamanca sobre participación, representación y Democracia, Salamanca, 3 y el 4 de abril de 2014.

${ }^{41}$ El necesario acotamiento del tema objeto de estudio impide la realización de un análisis detallado del contenido de las disposiciones sobre Buen Gobierno que presenta la Ley. Ello no obstante, cabe advertir que se trata de una regulación prescindible en su texto, en la medida en que el Informe sobre el Plan de Regeneración Democrática estudiado y aprobado el 20 de septiembre de 2013 por el Consejo de Ministros -y que se expondrá más adelante-, previó legislar el control del ejercicio del cargo público de la AGE donde, atendiendo al destino y a la naturaleza del marco constituido por los preceptos 25-32 de la Ley, hubiera encontrado una mejor adaptación. Véase: http//imagenes.publico.es/resources/archivos/2013/9/20 / 1379673017104medidasrajoy.pdf (Última consulta, 14 de julio de 2014).
} 
rencia y Buen Gobierno; y componer un plan formativo en el ámbito de la transparencia para funcionarios y personal de la AGE, así como dirigir una campaña informativa a los ciudadanos. Hay que señalar que esta última previsión -recogida en la disposición adicional séptima- es una de las novedades que la Ley presenta respecto al Proyecto de Ley, respondiendo, mediante la misma, a la petición doctrinal de añadir el cometido de organizar programas de preparación y concienciación que promuevan un cambio de actitud de la ciudadanía, en general, y de los sujetos que forman parte de la AP, en particular, en aras de emprender el camino hacia una cultura de transparencia, tanto a nivel externo, como interno.

Sin embargo, no haber llevado a cabo aún tales operaciones no justifica el excesivo periodo de adaptación fijado. A pesar de que, observando su carácter, podría aceptarse que se anuncian como actuaciones a realizar con anterioridad a la entrada en vigor de la Ley -ya que, en su mayoría, son previsiones que la misma efectúa para garantizar su correcta aplicación-, muchas otras normas, más amplias y complejas, no han precisado de tan desmesurado lapso de adecuación ${ }^{42}$. En consecuencia, no es de extrañar que se cuestione la verdadera voluntad política de someter la acción de los responsables públicos, y por ende, la propia actuación gubernativa, a un constante escrutinio de los ciudadanos. Incluso hay quien tacha la demora en cuestión de estrategia electoral en vista de las elecciones locales y autonómicas previstas para 2015, presuponiendo que, de lo contrario, se evidenciarían numerosas sombras u opacidades inoportunas. Lo que sí está claro es que no se puede hablar de transparencia y establecer, al mismo tiempo, medidas que aplazan la efectividad de una nueva regulación que, teóricamente al menos, trata de "incrementarla y reforzarla".

\section{ESTUDIO DE OTRAS INICIATIVAS LEGISLATIVAS}

Aunque la aprobación de la examinada Ley 19/2013 constituye un importante primer paso en la transformación, tanto formal como material, que la actuación pública española precisa, las múltiples insuficiencias que se han podido constatar en el apartado previo han motivado la puesta en marcha, en los diferentes niveles territoriales, de iniciativas de diversa índole, legislativas, principalmente.

\footnotetext{
42 Por ejemplo, la Ley 25/2009, de 22 de diciembre, de modificación de diversas leyes para su adaptación a la Ley sobre el libre acceso a las actividades de servicios y su ejercicio -también denominada Ley Ómnibus- entró en vigor, tal y como estableció su disposición final quinta, el 27 de diciembre de 2009, cuatro días después de su publicación en el Boletín Oficial del Estado, mientras que la Ley 27/2013, de 27 de diciembre, de racionalización y sostenibilidad de la Administración Local, está vigente desde el día siguiente al de su publicación, de acuerdo con su disposición final sexta.
} 


\section{1. Ámbito estatal}

Entre las medidas adoptadas en el plano estatal para lograr, junto con la Ley de transparencia, acceso a la información pública y buen gobierno, un cambio en el modelo de gestión imperante, destacan aquellas que recoge el Plan de Regeneración Democrática, así como las que derivan del articulado de la Ley de racionalización y sostenibilidad de la Administración Local.

\section{A. Plan de Regeneración Democrática}

El 13 de diciembre de 2013 el Consejo de Ministros aprobó el Plan de Regeneración Democrática que el Presidente del Gobierno anunció en el Debate sobre el Estado de la Nación celebrado en el mes de febrero de ese mismo año. Fue el Ministerio de la Presidencia el que asumió la coordinación de su diseño, donde destacan las aportaciones del Centro de Estudios Políticos y Constitucionales, y del resto de departamentos ministeriales.

El Informe sobre el Plan, de 20 de septiembre de $2013^{43}$, ya señaló que el Gobierno se sitúa, por razón de las propuestas recogidas y "taly como le demanda la sociedad española, en la vanguardia del impulso de las medidas de regeneración democrática, el fortalecimiento de las instituciones y la lucha contra la corrupción". Y es que se espera que las previsiones políticas, jurídicas y de orden práctico que lo componen doten de mayor transparencia a la actividad pública del país y que, en definitiva, protejan su carácter democrático.

Bien que son numerosas las leyes que se verán afectadas por el paquete legislativo en cuestión, el Ejecutivo ha querido definir el contenido de su núcleo esencial: el Proyecto de Ley Orgánica de control de la actividad económico-financiera de los Partidos Políticos ${ }^{44}$, por un lado, y el Proyecto de Ley reguladora del

43 CONSEjO DE Ministros. "Informe sobre el Plan Nacional de Regeneración Democrática": http://imagen es.publico.es/resources/archivos/2013/9/20/1379673017104medidasrajoy.pdf (Última consulta, 21 de mayo de 2014).

${ }^{44}$ España. Proyecto de Ley Orgánica 121/000082, de 25 de febrero de 2014, de control de la actividad económico-financiera de los Partidos Políticos, por la que se modifican la Ley Orgánica 8/2007, de 4 de julio, sobre financiación de los Partidos Políticos, la Ley Orgánica 6/2002, de 27 de junio, de Partidos Políticos, y la Ley Orgánica 2/1982, de 12 de mayo, del Tribunal de Cuentas. Boletin Oficial de las Cortes Generales, 28 de febrero de 2014, $\mathrm{n}^{\circ}$. 82-1, serie A. 
ejercicio de alto cargo de la $\mathrm{AGE}^{45}$, por otro, sin olvidar el Proyecto de Ley Orgánica de reforma del Código Penal (en adelante CP) ${ }^{46}$.

La Exposición de Motivos del primero de ellos basa su adopción en la necesidad legal de incluir "nuevas medidas de vigilancia de la actividad económico-financiera de los partidos políticos, con la que se avance aún más en la transparencia y control al que han de estar sometidos". Así, entre sus reformas prevalece, en lo que a este estudio atañe, la ampliación de la información económica y contable que los partidos políticos han de hacer pública, llevada a cabo a través de la modificación del artículo 14 del Título IV de la Ley Orgánica 8/2007, sobre financiación de los partidos políticos ${ }^{47}$. La actual denominación del precepto ya deja entrever dicha ampliación, puesto que ha pasado de mencionar sólo los "libros de contabilidad", a referirse a las "obligaciones relativas a la contabilidad de los partidos políticos". Éstos son los principales cambios que presenta: el añadido de las herencias y legados recibidos como categoría de ingreso mínima a contener en la cuenta de ingresos de los libros de Tesorería, Inventarios y Balances; el adelanto de la fecha límite para la remisión al Tribunal de Cuentas de las cuentas anuales consolidadas del 30 de junio al 31 de marzo del año siguiente al que aquéllas se refieran; la obligación del responsable de la gestión económico-financiera de enviar al Registro de partidos políticos del Ministerio de Interior, en el plazo de un mes, justificación emitida por el Tribunal de Cuentas de haber efectuado dicha remisión; y el deber de los partidos políticos de publicar en su página web, en un periodo máximo de 15 días, el informe de fiscalización correspondiente a un determinado ejercicio emitido por el Tribunal de Cuentas.

Por lo demás, con carácter más general, el Proyecto de Ley Orgánica muestra novedades tan relevantes como la prohibición absoluta de donaciones procedentes de personas jurídicas y de condonaciones de deuda por entidades de crédito, la exigencia a fundaciones y entidades vinculadas de inscribirse en el Registro de Partidos para concurrir a convocatorias de subvenciones, o la posibilidad de establecer fórmulas de colaboración entre el Tribunal de Cuentas y determinados organismos públicos y entidades de crédito para la obtención de la información necesaria para la correcta fiscalización de las cuentas.

${ }^{45}$ España. Proyecto de Ley 121/000083, de 25 de febrero de 2014, reguladora del ejercicio del alto cargo de la AGE. Boletín Oficial de las Cortes Generales, 28 de febrero de 2014, n . 83-1, serie A.

${ }^{46}$ España. Proyecto de Ley Orgánica 121/000064, de 1 de octubre de 2013, por la que se modifica la Ley Orgánica 10/1995, de 23 de noviembre, del Código Penal. Boletín Oficial de las Cortes Generales, 4 de octubre de 2013, nº.66-1, serie A.

${ }^{47}$ España. Ley Orgánica 8/2007, de 4 de julio, sobre financiación de los partidos políticos. Boletín Oficial del Estado, 5 de julio de 2007, nº. 160, p. 29010. 
El Proyecto de Ley reguladora del ejercicio del alto cargo de la AGE, por su parte, responde, según su Exposición de Motivos, a la precisión de aclarar, reforzar y ampliar el marco jurídico que regula el desarrollo de tal actividad, "con vistas a garantizar que [...] se realice con las máximas condiciones de transparencia, legalidad y ausencia de conflictos entre sus intereses privados y los inherentes a sus funciones públicas". Ello no obstante, cabe advertir que el objetivo fundamental de esta iniciativa es cubrir el vacío legal existente al respecto -es bien sabido que España ha carecido, hasta el momento, de un estatuto del cargo público- y que, tal y como reconoce el propio texto, "minaba el derecho de los ciudadanos a una información transparente, clara y comprensible de las condiciones aplicables".

A pesar de que entre sus estimables resultados no se encuentre la tan demandada aminoración del excesivo número de altos cargos que integra, a día de hoy, la AGE, es indiscutible que el Proyecto de Ley recoge importantes medidas concernientes a su actuación: aclara las condiciones para su nombramiento -entre las que cabe destacar la de idoneidad que fija el artículo 2 en sus dos primeros puntos-; determina la regulación relativa a la compensación tras su cese e introduce un procedimiento de examen de su situación patrimonial; concreta el régimen de conflictos de intereses y de incompatibilidades; detalla la forma en la que deben efectuar su declaración de actividades económicas y de bienes y derechos; regula los órganos de vigilancia y control, reforzando la Oficina de Conflicto de Intereses; y establece el régimen sancionador.

Exige, asimismo, mayor transparencia: además de regularla en su artículo 3 como principio rector que debe presidir la adopción de las decisiones de los altos cargos, la anuncia como criterio interpretativo de las disposiciones sancionadoras -en su aplicación-. Cabe añadir, en este contexto, que el Proyecto de Ley dedica su artículo 22 a precisar el carácter de la información que la Oficina de Conflicto de Intereses debe proporcionar y de las pautas procedimentales que en dicho cometido debe respetar, en aras de "asegurar la transparencia del control del régimen de incompatibilidades".

El citado artículo 3 somete la actuación del alto cargo, igualmente, a las disposiciones de buen gobierno recogidas en la Ley 19/2013. Y es que se trata, posiblemente, del principal destinatario de tal regulación. De ahí que, como se ha considerado previamente ${ }^{48}$, parezca más apropiada la inclusión de tales preceptos en este texto legal.

${ }^{48}$ Véase ref. 41. 
Y por último, el Proyecto de Ley Orgánica por la que se modifica la Ley Orgánica del CP, aunque muestra novedades de diversa índole, pone especial atención en la transformación de los delitos previstos para combatir la corrupción. Añade, así, la Sección 1 bis, "de la administración desleal", al Capítulo VI del Título XIII del Libro II que, comprendiendo un único artículo, tipifica, con carácter general, dicha modalidad delictiva. Hay que advertir, además, que pasa a regularla separada de los delitos de apropiación indebida, como un delito patrimonial. Es de destacar, también, que contempla la malversación como un supuesto de la administración desleal de fondos públicos por lo que, tal y como señala la Exposición de Motivos, "se incluyen dentro del ámbito de la norma, junto con las conductas de desviación y sustracción de los fondos públicos[...], otros supuestos de gestión desleal con perjuicio para el patrimonio público".

B. Ley 27/2013 de racionalización y sostenibilidad de la Administración Local

Dos de los objetivos básicos de la Ley 27/2013, de 27 de diciembre, de racionalización y sostenibilidad de la Administración Local ${ }^{49}$ están estrechamente relacionados al tema objeto de estudio: la racionalización de la estructura organizativa de la Administración Local, de acuerdo con los principios de eficiencia, estabilidad y sostenibilidad financiera, por un lado, y la garantía de un control financiero y presupuestario más riguroso, por otro.

Pero antes de proceder a analizar las concretas medidas que la nueva norma jurídica establece en torno a la transparencia, es preciso ofrecer una breve aproximación al significado que adquieren en la específica esfera del sector público, en general, y de la gestión de servicios e intereses públicos, en particular, los conceptos de racionalización y de sostenibilidad que dan nombre a la misma. Mientras que el primero es sintetizado, principalmente, por la mejora del rendimiento y la reducción de costos, o lo que es lo mismo, por la eficacia y la eficiencia -y, evidentemente, por su articulación-, el segundo debe entenderse ligado a propósitos de continuidad o mantenimiento y viabilidad, es decir, en términos de preservación y conciliación de los aspectos económicos, sociales y ambientales en la configuración y el funcionamiento diario de las $\mathrm{AAPP}^{50}$.

${ }^{49}$ España. Ley 27/2013, de 27 de diciembre, de racionalización y sostenibilidad de la Administración Local. Boletín Oficial del Estado, 30 de diciembre de 2013, nº. 312, p. 106430.

${ }^{50}$ ARNÁEZ ARCE, por ejemplo, se ha expresado en esta línea. ARNÁEZ ARCE, Vega María. La transparencia en el ámbito local tras la reforma de la Ley 27/2013. Ponencia presentada durante las III Jornadas BiscayLaw en la Universidad de Deusto sobre la autonomía local en tiempos de crisis, Bilbao, 30 y 31 de enero de 2014. 
Dicho esto, cabe indicar que, respecto al primero de los objetivos señalados, la Ley introduce un nuevo artículo 116 ter que comprende diversas obligaciones de transparencia. En efecto, impone a las Corporaciones Locales el deber de determinar, antes del día 1 de noviembre de cada año, el coste efectivo de los servicios que prestan, conforme a criterios comunes, esto es, partiendo de los datos contenidos en la liquidación del presupuesto general, y en su caso, de las cuentas anuales aprobadas en las entidades vinculadas o dependientes, correspondiente al ejercicio inmediato anterior, y teniendo en cuenta, asimismo, los costes reales directos e indirectos con arreglo a los datos de ejecución de gastos. Ordena, después, su remisión al Ministerio de Hacienda y Administraciones Públicas para su publicación y puesta a disposición de los ciudadanos. Según señala el Preámbulo de la Ley, tales previsiones constituyen "un paso fundamental en la mejora de la información disponible, eliminando asimetrias, para la toma de decisiones [...] contribuir de forma permanente al aumento de la eficiencia". Y es que, ciertamente, favorecen al cumplimiento del principio de eficiencia - en la asignación y utilización de los recursos públicos-, de conformidad con el artículo 7 de la Ley Orgánica 2/2012, de 27 de abril, de Estabilidad Presupuestaria y Sostenibilidad Financiera ${ }^{51}$.

Y en lo que a la garantía del control económico-presupuestario concierne, hay que apuntar, en lo que aquí interesa, a que la Ley, por una parte, refuerza el papel de la función interventora de las Entidades Locales, y por otra parte, atribuye al Estado, en relación a los funcionarios con habilitación de carácter nacional que prestan servicios en las Entidades Locales, tanto la selección, formación y habilitación, como la potestad sancionadora, en los casos de infracciones más graves. Tales modificaciones, como afirma el Preámbulo de la Ley, supondrán una mayor transparencia en la información económico-financiera de dichas Corporaciones, derivando en una manifiesta mejora de la toma de decisiones por los cargos electos en el ejercicio del mandato representativo que tienen encomendado constitucionalmente.

\section{2. Ámbito autonómico}

En el plano autonómico también se ha advertido la necesidad de garantizar y promover la transparencia en la gestión administrativa a través del ejercicio de un firme control institucional y de la puesta en marcha de diferentes estrategias normativas de protección y fomento. Y es que, si bien este último año ${ }^{52}$ sólo ha en-

${ }^{51}$ España. Ley Orgánica 2/2012, de 27 de abril, de Estabilidad presupuestaria y Sostenibilidad Financiera. Boletin Oficial del Estado, 30 de abril de 2012, nº 103, p. 32653.

${ }^{52}$ Echando la vista más atrás, cabe destacar que Galicia fue pionera en el establecimiento de una regulación autonómica acerca del tema que a este estudio atañe, a través de la aprobación de la Ley 
trado en vigor la Ley 4/2013, de 21 de mayo, de Gobierno Abierto de Extremadura $^{53}$, lo cierto es que muchas Comunidades tratan de apresurarse en la adaptación a las obligaciones de transparencia que impone la Ley 19/2013, dejando a un lado el plazo máximo de dos años previsto al respecto. Algunas de ellas se han comprometido, incluso, a subsanar los defectos que la misma presenta por medio de la aprobación de un precepto jurídico verdaderamente completo.

En cualquier caso, es preciso comenzar dando cuenta de que algunas Comunidades Autónomas gobernadas por el Partido Popular han considerado que la integración de la Ley 19/2013 en su ordenamiento jurídico basta para asegurar la efectividad de la noción de transparencia, por lo que han optado por limitar su actuación a la mera traslación. El Ejecutivo cántabro, por ejemplo, ha rechazado dotar al Legislativo regional del Código de Transparencia y Buen Gobierno propuesto por los grupos de la oposición ${ }^{54}$.

Otras Comunidades, entre las que destacan Aragón, La Rioja y Castilla y León, bien que ajustándose casi por completo al texto nacional, han preferido iniciar el proceso de elaboración de su propia ley. Y siguiendo esa misma línea, la Comunidad Valenciana y Castilla la Mancha también han manifestado su intención de confeccionar una norma particular.

4/2006, de 30 de junio, de transparencia y buenas prácticas de la AP gallega. Su importancia no sólo deriva del hecho de ser la primera norma que previó un conjunto de medidas para proteger e impulsar la transparencia de un sistema administrativo autonómico - entre las que sobresalen, por su carácter novedoso, aquellas referidas a la administración electrónica o la contratación-. Fijó además, ciertos preceptos que superaban la legislación básica estatal vigente: sus artículos 4 y 5 , por ejemplo, sobrepasaron lo recogido por el artículo 37 de la LRJAP-PAC al reconocer un derecho de acceso que comprendía como objeto, junto a archivos y registros, informaciones no formalizadas en documentos. Hay que señalar, ante todo, que pese a la presentación de leyes posteriores sobre materias albergadas, gran parte de sus mandatos rige todavía. Seis años después, Navarra, con la publicación de la Ley Foral 11/2012, de 21 de junio, de transparencia y gobierno abierto, constituyó otro referente autonómico acerca de la transparencia pública, que se adelantó, incluso, a las previsiones nacionales -en aquel momento en trámite-. Estudio detallado en: "Administrazio Publikoa eta gardentasuna. Nafarroako Foru Erkidegoaren eta Euskal Autonomia Erkidegoaren kasuen inguruko aipamen berezia". Revista Vasca de Administración Pública, nº. 97, 2013, pp. 61-96.

${ }^{53}$ Extremadura. Ley 4/2013, de 21 de mayo, de Gobierno Abierto de Extremadura. Diario Oficial de Extremadura, 24 de mayo de 2013, nº. 99, p. 11650.

${ }^{54}$ Pese a que todavía no se pueda concluir el mayor o menor peso de las concretas normas autonómicas sobre la materia que aquí ocupa en su salvaguarda y desarrollo, hay que señalar que el Parlamento de Cantabria ha conseguido el primer puesto en el Índice de Transparencia de los Parlamentos (IPAR) del año 2013 elaborado por la organización no gubernamental Transparencia Internacional. Véase: http:// transparencia.org.es/IPAR/INDICE_IPAR_2013.html (Última consulta, 21 de julio de 2014). 
Pero en lo que aquí interesa, son ciertos mandatos de la reciente Ley de Transparencia Pública de Andalucía ${ }^{55}$, así como del Proyecto de Ley del Principado de Asturias de Transparencia ${ }^{56}$, quienes requieren especial atención, dado que sus impulsores dicen haberlos empleado como medio de enmendación de los errores que a su juicio presenta la regulación estatal.

En efecto, la primera afirma, en su Exposición de Motivos, que tiene por objeto "el desarrollo de la normativa básica estatal[...], ahondando, en la medida de sus posibilidades, en la ampliación del ámbito de la actividad que se somete a la transparencia", en aras de constituir un referente en materia de transparencia y acceso a la información pública. Y, ciertamente, los expertos no han tardado en calificarla de avanzada y valiente.

Se observan varias mejoras respecto a la Ley 19/2013. En primer lugar, cabe apuntar a que cede la regulación del buen gobierno al futuro Estatuto de Altos Cargos de la Junta de Andalucía, evitando mezclarla con las disposiciones sobre transparencia. Su artículo 1 indica, así, que "la presente Ley tiene por objeto la regulación, en el ámbito de la Comunidad Autónoma de Andalucía, de la transparencia en su doble vertiente de publicidad activa y de derecho de acceso a la información pública, como instrumento para facilitar el conocimiento de la ciudadanía de la actividad de los poderes públicos y de las entidades con financiación pública, promoviendo el ejercicio responsable de dicha actividad y el desarrollo de una conciencia ciudadana y democrática plena". En segundo lugar, y en lo que al derecho de acceso a la información pública concierne, se puede comprobar que facilita su ejercicio mediante la promoción de la tramitación electrónica (artículo 29), por un lado, y la limitación del uso de las causas de inadmisión señaladas en la legislación básica (artículo 30), por otro. En tercer lugar, es de destacar que dedica, de forma íntegra, su Título IV al fomento de la transparencia, estableciendo, por ejemplo, diversas iniciativas de interoperabilidad, formación, y divulgación y difusión institucional. En cuarto lugar, prevé una autoridad única, el Consejo de Transparencia y Protección de Datos de Andalucía, en materia de transparencia y protección de datos, eludiendo crear dos entidades diferentes, o lo que es lo mismo, consiguiendo una economía organizativa, y salvando posibles contradicciones entre las mismas. $\mathrm{Al}$ respecto, cabe afirmar que, mientras que, como se ha dicho, se espera que el órgano de control y supervisión estatal

${ }^{55}$ Andalucía. Ley 1/2014, de 24 de junio, de Transparencia Pública de Andalucía. Boletín Oficial de la Funta de Andalucía, 30 de junio de 2014, nº. 124, p. 10.

56 Véase: Proyecto de Ley del Principado de Asturias de Transparencia: http://www.asturias.es/web asturias/GOBIERNO/TRANSPARENCIA/proyecto_ley_transparencia.pdf (Última consulta, 21 de julio de 2014). 
esté adscrito al Ministerio de Hacienda y Administraciones Públicas, la Consejería de la Presidencia únicamente llevará a cabo la relación del Consejo de Transparencia y Protección de Datos de Andalucía con la Administración de la Junta -sin ningún tipo de dependencia-. El Consejo albergará, además, un órgano de participación y consulta denominado Comisión Consultiva de la Transparencia y la Protección de Datos. Y en quinto y último lugar, llama la atención el firme régimen sancionador que la Ley ha incluido en su articulado.

A todo eso hay que añadir la ampliación del ámbito subjetivo de aplicación de la norma que determinó la Comisión de la Presidencia del Parlamento andaluz por medio de la aprobación, el 27 de mayo, del Dictamen sobre su Proyecto de Ley. Más concretamente, introdujo en el artículo 5 "a las iglesias, confesiones, comunidades y otras entidades inscritas en el Registro de Entidades Religiosas" como sujetos obligados ${ }^{57}$. Cabe mencionar, de todos modos, que la redacción inicial del precepto señalado ya adelantaba a su equivalente estatal, puesto que comprendía, junto a los partidos políticos y las organizaciones sindicales y empresariales, a las corporaciones, asociaciones, instituciones y entidades representativas de intereses colectivos y otras entidades.

Pero no todo son ventajas. Y es que no se ha reconocido el carácter fundamental del derecho de acceso a la información pública, no se han concretado los límites previstos en la legislación básica, no se ha prescindido de la figura del silencio administrativo, y no se han definido, de forma adecuada, las funciones y potestades del Consejo, entre otros.

El Proyecto de Ley del Principado de Asturias de Transparencia, aprobado por Acuerdo de Consejo de Gobierno de 9 de abril, presenta, igualmente, una clara mejoría respecto a ciertos aspectos de la Ley 19/2013: está siendo tramitado de forma paralela al Proyecto de Ley de Buen Gobierno e Incompatibilidades de Altos Cargos, aunque inicialmente fueran concebidos como una única norma, lo que refleja la voluntad del legislador asturiano de separar las reglas de buen gobierno, al igual que en el precepto andaluz, del marco jurídico otorgado a la transparencia, con el propósito de hacer frente a la complejidad que derivaría de su unión y evitar controversias; contiene un amplio ámbito subjetivo de aplicación en lo referente a los principios y obligaciones de publicidad activa, ya que lo extiende a los partidos políticos, sindicatos y organizaciones empresariales de ámbito autonómico, así como a las entidades privadas que perciben ayudas o subvenciones públicas en una cuantía superior a 50.000 euros, o cuando al menos el

${ }^{57}$ Para más detalle, véase: http://sevilla.abc.es/andalucia/20140528/sevi-iglesia-transparencia-altos-cargos -201405281131.html (Última consulta, 23 de julio de 2014). 
40 por 100 del total de sus ingresos anuales tengan dicho carácter y alcancen un mínimo de 3.000 euros $^{58}$; en su artículo 8 prevé la elaboración y aprobación de un plan estratégico de transparencia en cada legislatura que aborde las medidas que contribuyan a promover y desarrollar las políticas autonómicas en la materia; y acorta, en su disposición final segunda, la vacatio legis establecida por el texto nacional para la adaptación a sus obligaciones por los órganos de las Comunidades Autónomas y Entidades Locales, fijando un único plazo de seis meses desde su publicación en el Boletín Oficial del Principado de Asturias para su entrada en vigor, tiempo que se estima necesario, tal y como recoge la Exposición de Motivos, "para poner en marcha los distintos mecanismos de transparencia y participación [...], así como adecuar la estructura administrativa al desarrollo de las funciones y objetivos establecidos $[\ldots]$ “..

Hay que señalar, no obstante, que también presenta algunos defectos e insuficiencias que, en su mayoría, coinciden con los concluidos tras el examen de la Ley de Transparencia Pública de Andalucía.

\section{CONGLUSIONES}

Primera. La solución al descalabro que los últimos años vive el sistema político-administrativo español a raíz, principalmente, de la crisis económico-financiera y de las prácticas de corrupción, pasa por que se reconozca, sin matices, que la transparencia pública es uno de los ejes vertebradores del carácter democrático de un país. Más concretamente, se debe asumir la importancia de que la ciudadanía conozca y comprenda los detalles de las decisiones adoptadas y de la gestión llevada a cabo por los órganos que conforman la AP, puesto que, además de propiciar la participación y la colaboración social en las mismas, resulta esencial para su legitimación.

Segunda. En vista de ello, hay que afirmar que la reciente Ley 19/2013, de 9 de diciembre, de transparencia, acceso a la información pública y buen gobierno no garantiza la eficacia del contenido de la noción de transparencia. No lo hace, al menos, de forma que quepa vaticinarla como definitoria del cambio de paradigma requerido. $Y$ es que se observan defectos tan relevantes como la introducción de un objeto fraccionable, la fijación de un incompleto ámbito subje-

58 La norma estatal es menos exigente, ya que prevé importes inferiores: “[...]en una cuantía superior a 100.000 euros o cuando al menos el 40\% del total de sus ingresos anuales tengan carácter de ayuda o subvención pública, siempre que alcancen como mínimo la cantidad de 5.000 euros" (artículo 3.b). 
tivo de aplicación, la inclusión de unos límites indeterminados, el establecimiento de un doble silencio administrativo negativo, la creación de un órgano de supervisión y control a todas luces dependiente o la previsión de una desmesurada vacatio legis.

De todos modos, en tanto que la calidad de la ejecución de la citada norma y del resto de preceptos legales, bien estatales, bien autonómicos, aprobados al respecto queda pendiente del ejercicio que lleven a cabo las propias autoridades públicas, así como de los diversos fallos que los Tribunales deban dictar-del referido a la naturaleza jurídica del derecho de acceso a la información pública, especialmente-, se puede apuntar a que, al constituir la base sobre la cual se debe construir a partir de ahora una auténtica cultura de transparencia, se erigen como la puerta que da entrada a la misma.

Tercera. Los canales de relación digital que han abierto las nuevas tecnologías de la información y de la comunicación -los Portales de Open Data y Open Government, por ejemplo- desempeñarán un papel primordial en el proceso de transformación emprendido, exigiendo la instauración de mecanismos de control que aseguren y promuevan la transparencia de sus implicaciones. También lo hará la puesta en marcha de iniciativas y dinámicas de concienciación ciudadana, formación, fomento y/o cooperación interinstitucional. Las posibilidades de seguir investigando al respecto son, por consiguiente, interesantes. Pero la clave para la consecución de una configuración y un desarrollo justos de la acción administrativa reside, sin lugar a dudas, en la voluntad de restaurar una ética pública donde la transparencia predomine en la búsqueda del bien común. Porque el propósito de potenciar los específicos valores morales y modelos de conducta que integran la buena administración conduce hacia la consolidación de la democracia, y ésta, ni se percibe, ni se logra, sin transparencia.

\section{BIBLIOGRAFÍA}

ARENA, Francisco Gregorio. "Transparencia administrativa y democracia". Revista Vasca de Administración Pública, no. 37, 1993, pp. 9-20.

ARNÁEZ ARCE, Vega María. La transparencia en el ámbito local tras la reforma de la Ley 27/2013. Ponencia presentada durante las III Jornadas BiscayLaw en la Universidad de Deusto sobre la autonomía local en tiempos de crisis, Bilbao, 30 y 31 de enero de 2014.

cotino Hueso, Lorenzo. Teoría y realidad de la transparencia pública en Europa. Tirant lo Blanch, Valencia, 2003. 
DOS ReIS COndesso, Fernando. Crisis del sistema político. Transparencia de los Poderes Públicos. Dykinson, Madrid, 2011.

ENÉRIZ OLAECHEA, Francisco Javier. "El proyecto de Ley de Transparencia: transparencia de la actividad pública y publicidad activa". Revista Aranzadi Doctrinal, $n^{\circ}$. 1/2013, Aranzadi, 2013, pp. 1-9.

FERnÁNDEZ RAMOS, Severiano. Panorámica general sobre transparencia y gobierno abierto. El estado actual de la situación en el Estado español. Ponencia presentada durante la sesión de Q-Epea en el Parlamento Vasco sobre Transparencia y Gobierno abierto de las instituciones y Administraciones Públicas, Vitoria, 23 de octubre de 2013.

-"Transparencia y Acceso a la Información Pública”. En: FERnÁNDEZ RAMOS, Severiano, y PÉREz Monguió, José María. Transparencia, Acceso a la Información Pública y Buen Gobierno. Ley 19/2013, de 9 de diciembre. Aranzadi, Pamplona, 2014.

GARCíA MACHO, Ricardo. "La transparencia en el sector público". En: BLASco esteve, Avelino (Coord.). El Derecho Público de la crisis económica. Transparencia y sector público. Hacia un nuevo Derecho Administrativo. Instituto Nacional de Administración Pública, Madrid, 2011, pp. 249-260.

GUichot REINA, Emilio. "El proyecto de ley de Transparencia y acceso a la información pública y el margen de actuación de las Comunidades Autónomas". Revista Andaluza de Administración Pública, nº. 84, 2012, pp. 89-134.

- Transparencia y acceso a la información en el Derecho europeo. Cuadernos Universitarios de Derecho Administrativo, Derecho Global, Global Law Press, Sevilla, 2011.

- Transparencia y acceso a la información pública en España: Análisis y propuestas legislativas. Fundación Alternativas, Madrid, 2011.

- Transparencia y buen gobierno. Aranzadi, Pamplona, 2014.

MARZO PORTERA, Ana. "Los límites legales a un gobierno transparente". Actualidad Jurídica Aranzadi, n. 841/2012, Aranzadi, 2012, pp. 1-3.

OLMEDO PALAcios, Manuel. "La Ley 19/2013, de 9 de diciembre, de transparencia, acceso a la información y buen gobierno". Diario La Ley, n. 8237, LA LEY, 2014, pp. 1-15. 
RAZQUIN LIZARRAGA, José Antonio. "De la intervención administrativa previa al control a posteriori: la reforma del procedimiento administrativo común a consecuencia de la directiva de servicios". Revista Aranzadi Doctrinal, n. 2/2010, Aranzadi, 2010, pp. 1-12.

-"El impacto de la directiva de servicios en el procedimiento administrativo: autorización, declaración responsable y comunicación". Revista furídica de Navarra, $\mathrm{n}^{\circ} .49,2010$, pp. 85-136.

SÁNCHEZ DE DIEGo FERnÁndez DE la RIVA, Manuel (Coord.). El derecho de acceso a la información pública. Actas del Seminario Internacional Complutense, Madrid, 27 y 28 de junio de 2007.

- El principio de transparencia y el derecho de acceso a la información pública. Ponencia presentada durante el XII Congreso de Constitucionalistas de España en la vieja Universidad de Salamanca sobre participación, representación y Democracia, Salamanca, 3 y el 4 de abril de 2014.

SENDín GARCíA, Miguel Ángel. "El derecho de acceso a los documentos administrativos: un instrumento esencial para la participación ciudadana". Revista de Estudios de la Administración Local y Autonómica, nº. 294-295, 2004, pp. 385-437.

SERra NAVARro, Pilar. Los archivos y el acceso a la documentación. Ministerio de Cultura, Madrid, 1980.

SMITH, Alfred Emanuel. "The future: Needed for America: Fewer Claims, More Growth". Time Magazine, Nueva York, 10 de noviembre de 1975: http://content.time. com/time/magazine/article/0,9171,913672,00.html (Última consulta, 7 de julio de 2014).

VELASco Rico, Clara Isabel. "Análisis en clave competencial del Proyecto de Ley estatal sobre Transparencia, Acceso a la Información Pública y Buen Gobierno". Revista d'Estudis Autonòmics i Federals, n. 17, 2013, pp. 279-328. 